\title{
KARAKTERISTIK, KESESUAIAN, DAN PENGELOLAAN LAHAN UNTUK TAMBAK BUDIDAYA DI KABUPATEN LUWU UTARA PROVINSI SULAWESI SELATAN
}

\author{
Hasnawi dan Akhmad Mustafa \\ Balai Riset Perikanan Budidaya Air Payau \\ Jl. Makmur Dg. Sitakka No. 129, Maros, Sulawesi Selatan 90511 \\ E-mail:vhalowi05@yahoo.co.id
}

(Naskah diterima: 21 Januari 2010; Disetujui publikasi: 24 September 2010)

\begin{abstract}
ABSTRAK
Kabupaten Luwu Utara (Lutra) memiliki lahan potensial untuk tambak dan produktivitas tambaknya untuk budidaya udang dan ikan relatif rendah. Oleh karena itu, dilakukan survai untuk mengetahui karakteristik lahan dalam upaya menentukan kesesuaian dan pengelolaan lahan untuk budidaya tambak demi peningkatan produktivitas tambak di Kabupaten Lutra. Faktor yang dipertimbangkan dalam mengetahui karakteristik lahan adalah: tanah, topografi, hidrologi, vegetasi, dan iklim. Analisis spasial dalam Sistem Informasi Geografis digunakan untuk penentuan kesesuaian lahan budidaya tambak. Pengelolaan lahan ditentukan berdasarkan karakteristik lahan yang disesuaikan dengan teknologi dan komoditas yang dapat diaplikasikan di tambak. Kawasan pesisir Kabupaten Lutra didominasi oleh tanah bermasalah yaitu tanah sulfat masam, tanah gambut, dan tanah sulfat masam yang berasosiasi dengan tanah gambut. Tanah sulfat masam adalah jenis tanah dominan di Kabupaten Lutra yang memiliki potensi kemasaman dan unsur-unsur toksik yang tinggi dan sebaliknya unsur hara makro yang rendah dengan tekstur tanah yang tergolong pasir berlempung dan lempung berpasir. Topografi lahan umumnya relatif datar dan elevasi yang tergolong rendah yang didominasi oleh vegetasi Sonneratia sp., Rhizophora sp., dan Nypa fruticans. Curah hujan yang rendah pada bulan September sampai Februari berdampak pada kondisi kualitas air yang lebih baik terutama pada salinitas, $\mathrm{pH}, \mathrm{Ca}$, dan $\mathrm{Mg}$ yang lebih tinggi daripada musim hujan. Hasil analisis menunjukkan bahwa lahan tambak di Kabupaten Lutra yang tergolong sangat sesuai (kelas S1) seluas 1.821,9 ha; tergolong cukup sesuai (kelas S2) seluas 368,2 ha; dan tergolong sesuai marjinal (kelas S3) seluas $3.268,1$ ha. Untuk perbaikan tanah bermasalah tersebut dapat dilakukan melalui remediasi maupun dengan pemupukan.
\end{abstract}

KATA KUNCl: karakteristik, kesesuaian, pengelolaan, lahan, tambak, Luwu Utara

ABSTRACT: Characteristics, suitability, and management of land for brackishwater ponds in North Luwu Regency South Sulawesi Province. By: Hasnawi and Akhmad Mustafa

Coastal area of North Luwu Regency has suitable areas for brackishwater ponds, however many of those areas are low in productivity for shrimp and fish culture. Hence, a survey was conducted to study the characteristics of the area as an effort to determine land suitability and land management for increasing the productivity of brackishwater ponds in North Luwu Regency. Factors that were taken into acount to determine the characteristics of land were soil, topography, hydrology, vegetation and climate condition. Spatial analysis using Geographical Information System 
software was used to determine land suitability for brackishwater ponds. Land management was determined based on the characteristics of land that are adaptable to the types of technology and commodity applied in the brackishwater ponds. The coastal area of North Luwu Regency was dominated by types of infertile soils, i.e., acid sulfate soil, peat soil and acid sulfate soil associated with peat soil, Acid sulfate soil in North Luwu Regency has high potential acidity and high level toxic element. On the other hand, the area has low level macro elements and soil textures are dominated by loamy sand and sandy loam. In general, the land topography is flat and the elevation is classified as low. The areas are dominated by Sonneratia sp., Rhizophora sp., and Nypa fruticans. Low rainfall level is occurred in September to February and directly affects the coastal water quality, causing higher salinity, $\mathrm{pH}, \mathrm{Ca}$, and $\mathrm{Mg}$ than in rainy season. Results of analysis show that brackishwater ponds in North Luwu Regency were classified as highly suitable (1,821.9 ha), moderately suitable $(368.2 \mathrm{ha})$ and marginally suitable $(3,268.1 \mathrm{ha})$. Remediation and fertilization are highly recommended in order to improve the soil quality for optimum culture production.

\section{KEYWORDS: characteristic, suitability, management, land, brackishwater ponds, North Luwu}

\section{PENDAHULUAN}

Sampai tahun 2005, luas tambak di pantai timur Provinsi Sulawesi Selatan mencapai 42.839 ha (Anonim, 2005). Tambak tersebut tersebar di Kabupaten Luwu Timur (Lutim), Luwu Utara (Lutra), Luwu, Wajo, Bone, dan Sinjai serta Kota Palopo dengan luas masing-masing berturut-turut $5.441,7.628,4.408,12.988$, $10.810,678$, dan 916 ha. Produktivitas tambak di pantai timur Provinsi Sulawesi Selatan tergolong tinggi untuk rumput laut (Gracilaria verrucosa), namun masih tergolong rendah, terutama untuk udang windu (Penaeus monodon) dan ikan bandeng (Chanos chanos) dan secara umum dilakukan dengan teknologi tradisional. Pantai timur Sulawesi Selatan, termasuk Kabupaten Lutra juga masih memiliki potensial lahan seluas 15.000 ha untuk budidaya tambak (DKP, 2005). Dengan demikian, masih ada peluang peningkatan produksi budidaya tambak di pantai timur Sulawesi Selatan, baik melalui diversifikasi, intensifikasi maupun ekstensifikasi.

Dalam kaitannya dengan sumberdaya alam, dikenal istilah lahan yang merupakan suatu lingkungan fisik yang terdiri atas tanah, topografi, hidrologi, vegetasi, dan iklim di mana pada batas-batas tertentu mempengaruhi kemampuan penggunaan lahan (FAO, 1976 dalam Rayes, 2007). Oleh karena itu, perbedaan kombinasi penyusun lingkungan fisik lahan tersebut akan memberikan karakteristik lahan yang berbeda dan pada akhirnya kesesuaian dan pengelolaan lahan yang berbeda pula.
Kesesuaian lahan adalah tingkat kecocokan suatu bidang lahan untuk penggunaan tertentu, seperti untuk budidaya tambak. Evaluasi kesesuaian lahan untuk budidaya tambak perlu dilakukan agar menjadi dasar pertimbangan dalam pengambilan keputusan penggunaan lahan yang sesuai dengan kesesuaiannya. Menurut Rossiter (1996), evaluasi kesesuaian lahan sangat penting dilakukan karena lahan memiliki sifat fisik, sosial, ekonomi, dan geografi yang bervariasi atau lahan diciptakan tidak sama. Sifat yang bervariasi dari lahan tersebut dapat mempengaruhi penggunaan lahan tersebut.

Evaluasi kesesuaian lahan merupakan suatu proses pendugaan keragaan lahan apabila lahan digunakan untuk tujuan tertentu (FAO, 1985) atau sebagai metode yang menjelaskan atau memprediksi kegunaan potensial dari Iahan (van Diepen et al., 1991). Apabila potensi lahan sudah dapat ditentukan, maka perencanaan penggunaan lahan dapat dilakukan berdasarkan pertimbangan yang rasional, paling tidak mengenai apa yang dapat ditawarkan oleh sumberdaya lahan tersebut (FAO, 1995 dalam Rayes, 2007). Dengan demikian, evaluasi kesesuaian lahan merupakan alat perencanaan penggunaan lahan yang strategis. Evaluasi kesesuaian Iahan memprediksi keragaan lahan mengenai keuntungan yang diharapkan dari penggunaan lahan dan kendala penggunaan lahan yang produktif serta degradasi lingkungan yang diperkirakan akan terjadi karena penggunaan lahan. Kesesuaian lahan merupakan suatu kunci sukses dalam kegiatan akuakultur yang 
mempengaruhi keberhasilan dan keberlanjutannya (Pérez et al., 2003).

Pengelolaan lahan yang tepat dapat meningkatkan produktivitas lahan termasuk lahan budidaya tambak dengan penggunaan masukan yang seminimal mungkin dan tidak menyebabkan terjadinya degradasi lingkungan. Setiap jenis lahan memiliki karakteristik tersendiri, sehingga pengelolaan lahan juga bersifat khas terhadap penggunaan lahan tersebut.

Oleh karena itu, dilakukan penelitian yang bertujuan untuk mengetahui karakteristik lahan sebagai upaya untuk menentukan kesesuaian dan pengelolaan lahan untuk budidaya tambak agar produktivitas tambak dapat meningkat dan berkelanjutan serta dapat menjadi acuan Pemerintah Kabupaten Lutra secara khusus dan Pemerintah Provinsi Sulawesi Selatan secara umum dalam penentuan Rencana Tata Ruang Wilayah.

\section{BAHAN DAN METODE}

Penelitian dilaksanakan di Kabupaten Lutra Provinsi Sulawesi Selatan. Lokasi penelitian adalah wilayah pesisir Kecamatan Bonebone, Malangke, Malangke Barat, dan Sukamaju.

Data primer yang dikumpulkan meliputi data biofisik lahan yaitu: tanah, topografi, hidrologi, dan vegetasi. Penentuan titik-titik pengambilan contoh tanah didasarkan pada peta Satuan Unit. Peubah kualitas tanah yang diukur langsung di lapangan adalah $\mathrm{pH}_{\mathrm{F}}$ ( $\mathrm{pH}$ tanah yang diukur di lapangan) dengan $\mathrm{pH}$-meter (Ahern \& Rayment, 1998) dan $\mathrm{pH}_{\mathrm{FOX}}$ ( $\mathrm{pH}$ tanah yang diukur di lapangan setelah dioksidasi dengan hidrogen peroksida $\left(\mathrm{H}_{2} \mathrm{O}_{2}\right)$ $30 \%$ ) dengan $\mathrm{pH}$-meter (Ahern \& Rayment, 1998) serta potensial redoks dengan redoxmeter. Contoh tanah diambil pada tiga kedalaman tanah yaitu $0-0,2 ; 0,4-0,6$; dan 0,8-1,0 m dari permukaan tanah. Untuk analisis peubah kualitas tanah lainnya, maka contoh tanah yang ada secepatnya dimasukkan dalam kantong plastik dan selanjutnya dimasukkan dalam cold box yang diberi es. Contoh tanah diovenkan pada suhu $80^{\circ} \mathrm{C}-85^{\circ} \mathrm{C}$ selama 48 jam (Ahern \& Blunden, 1998). Setelah kering, contoh tanah dihaluskan dengan cara ditumbuk pada lumpang porselin dan diayak dengan ayakan ukuran lubang $2 \mathrm{~mm}$ dan selanjutnya dianalisis di Laboratorium Tanah Balai Riset Perikanan Budidaya Air Payau (BRPBAP) di Maros. Peubah kualitas tanah yang dianalisis di laboratorium meliputi peroxide oxidisable sulfur $\left(\mathrm{S}_{\mathrm{POS}}\right)$, total potential acidity (TPA), pirit (Ahern \& Rayment, 1998; Ahern et al., 1998a, 1998b), bahan organik dengan metode ignition loss (Melville, 1993), Fe dengan spektrofotometer serapan atom (SSA), Al dengan SSA, $\mathrm{PO}_{4}$ dengan metode Olsen atau Bray 1 (Sulaeman et al., 2005) dan tekstur dengan metode hidrometer (Bouyoucos, 1962).

Topografi diketahui melalui pengamatan di lapangan dan berdasarkan peta Satuan Unit. Data hidrologi yang diukur adalah pasang surut dan kualitas air. Pengukuran pasang surut dilakukan di salah satu titik pengamatan yang terletak di perairan Teluk Bone yaitu di Desa Munte, Kecamatan Bonebone, Kabupaten Lutra. Pengukuran pasang surut dilakukan selama 39 jam dengan interval pengukuran 1 jam menggunakan palem atau rambu pengamat pasang surut. Pengukuran dan pengambilan contoh air dilakukan di sungai, laut, saluran, dan tambak yang dilakukan pada musim kemarau dan musim hujan. Pengukuran dan pengambilan contoh air di tambak mengikuti titik pengambilan contoh tanah. Peubah kualitas air yang diukur langsung di lapangan adalah suhu, salinitas, oksigen terlarut, dan $\mathrm{pH}$ dengan menggunakan Hydrolab ${ }^{*}$ Minisonde. Contoh air untuk analisis di laboratorium diambil dengan menggunakan Kemmerer Water Sampler dan dipreservasi mengikuti petunjuk APHA (2005). Peubah kualitas air yang dianalisis di Laboratorium Air Balai Riset Perikanan Budidaya Air Payau (BRPBAP) di Maros meliputi: $\mathrm{NH}_{4}, \mathrm{NO}_{3}, \mathrm{NO}_{2}, \mathrm{PO}_{4}$, $\mathrm{SiO}_{2}, \mathrm{SO}_{4}, \mathrm{Fe}$, kesadahan $\mathrm{Ca}$, kesadahan $\mathrm{Mg}$, kesadahan total dan padatan tersuspensi total mengikuti petunjuk Menon (1973), Parsons et al. (1989), dan APHA (2005).

Spesies vegetasi mangrove diketahui dengan mencatat setiap jenis vegetasi mangrove yang ditemui. Identifikasi dan klasifikasi vegetasi mangrove ditentukan berdasarkan petunjuk Blasco (1984), Chapman (1984), dan Cintrõn \& Novelli (1984). Seluruh titik-titik pengamatan dan pengambilan contoh ditentukan titik koordinatnya dengan menggunakan Global Positioning System (GPS).

Data sekunder dikumpulkan melalui penelusuran berbagai laporan, pustaka dan hasil penelitian dari berbagai instansi terkait. Peta yang dikumpulkan antara lain peta Jenis Tanah skala 1:250.000 Provinsi Sulawesi 
Selatan, peta Curah Hujan Tahunan Provinsi Sulawesi Selatan, peta Kelerengan Kabupaten Lutra dan peta Administrasi Kabupaten Lutra.

Peta Penutup/Penggunaan Lahan yang digunakan adalah yang diproduksi oleh Paena et al. (2008) yang berasal dari hasil klasifikasi Citra Landsat-7 ETM $^{+}$dengan Program Er Mapper 7.1 yang diintegrasikan dengan peta dasar dari peta Rupabumi Indonesia.

Peta penutup/penggunaan lahan disatukan dengan peta bentuk lahan untuk mendapatkan peta satuan unit untuk digunakan sebagai acuan dalam survai lapang yaitu penentuan titik-titik pengambilan contoh seperti disebutkan sebelumnya. Informasi spasial lain yang diperoleh dari data primer dan sekunder juga diintegrasikan dengan peta penutup/penggunaan lahan.

Data primer, sekunder, dan peta penutup/ penggunaan lahan yang sudah dikumpulkan, selanjutnya dilakukan pengolahan data dengan menggunakan analisis spasial dalam Sistem Informasi Geografis (SIG) (Purwadhi, 1999). Pada proses analisis menggunakan program ArcView 3.3 dengan cara memasukkan setiap peubah data untuk menghasilkan peta tematik bagi setiap peubah data. Bobot total setiap peubah data diperoleh dengan cara mengalikan nilai dari setiap peubah dengan bobot relatifnya. Pada setiap faktor ditentukan bobot kumulatifnya dengan menambahkan bobot relatif setiap peubah. Selanjutnya dilakukan proses tumpang tindih pada semua peubah untuk penghitungan kembali bobot kumulatif untuk semua faktor. Pemberian kode ulang dari bobot kumulatif ini mempresentasikan kontribusi atribut dan faktor terhadap tingkat kesesuaian lahan. Kriteria yang digunakan dalam penentuan kesesuaian lahan untuk budidaya tambak mengacu pada kriteria yang ada (Mustafa et al., 2007b).

Asumsi yang diterapkan dalam evaluasi kesesuaian lahan tambak adalah usaha perbaikan lahan untuk mendapatkan kondisi potensial dipertimbangkan dan disesuaikan pada pengelolaan yang rendah atau sederhana sampai sedang. Hasil proses penilaian kesesuaian lahan ditampilkan dalam bentuk sistem klasifikasi kesesuaian lahan. Sistem klasfikasi kesesuaian lahan ditentukan sampai tingkat kategori Kelas. Pada kategori Kelas, kelas-kelas kesesuaian lahan adalah sebagai berikut: (a) Kelas sangat sesuai (kelas S1): lahan ini tidak mempunyai faktor pembatas yang berarti untuk penggunaan terhadap suatu peruntukan secara berkelanjutan atau hanya sedikit faktor pembatas yang tidak akan mempengaruhi produktivitas; (b) Kelas cukup sesuai (kelas S2): Iahan ini mempunyai faktor pembatas yang agak berarti untuk penggunaan berkelanjutan dan dapat menurunkan produktivitas; dan (c) Kelas sesuai marjinal (kelas S3): Iahan ini mempunyai faktor pembatas yang berat untuk penggunaan berkelanjutan dan akan mengurangi produktivitas; dan (d) Kelas tidak sesuai (kelas N): Iahan ini mempunyai faktor pembatas yang sangat berat dan permanen yang dapat menghalangi kemungkinan pemanfaatannya. Pengelolaan lahan yang direkomendasikan didasarkan pada karakteristik lahan dan disesuaikan dengan tingkat teknologi dan komoditas yang diaplikasikan di tambak.

\section{HASIL DAN BAHASAN}

\section{Karakteristik Lahan}

Kabupaten Lutra terdiri atas 11 kecamatan yaitu: Malangke Barat, Malangke, Sukamaju, Bonebone, Baebunta, Mappedeceng, Sabbang, Masamba, Limbong, Rampi, dan Seko serta hanya 4 kecamatan yang disebut pertama yang memiliki lahan budidaya tambak. Oleh karena itu, karakterisasi lahan hanya dilakukan di Kecamatan Malangke Barat, Malangke, Sukamaju, dan Bonebone. Telah disebutkan sebelumnya bahwa lahan merupakan suatu lingkungan fisik yang terdiri atas tanah, topografi, hidrologi, vegetasi, dan iklim. Oleh karena itu, setiap bagian dari lahan tersebut akan dibahas pada bagian berikut.

\section{Tanah}

Jenis tanah yang dijumpai di kawasan pertambakan Kabupaten Lutra didominasi oleh tanah sulfat masam dan sebagian kecil tanah gambut dan tanah sulfat masam yang berasosiasi dengan tanah gambut. Karakteristik tanah di setiap kecamatan yang memiliki tambak di Kabupaten Lutra terlihat pada Tabel 1.

$\mathrm{pH}_{\mathrm{F}}$ adalah $\mathrm{pH}$ tanah yang diukur di lapangan dalam kondisi tanah jenuh dengan air, sedangkan $\mathrm{pH}_{\mathrm{FOX}}$ adalah $\mathrm{pH}$ tanah yang diukur di lapangan setelah dioksidasi sempurna dengan $\mathrm{H}_{2} \mathrm{O}_{2}$ (hidrogen peroksida) 30\% (Ahern \& Rayment, 1998). $\mathrm{pH}_{\mathrm{F}}$ tanah relatif 
sama di setiap kecamatan, sedangkan $\mathrm{pH}_{\mathrm{Fox}}$ cenderung bervariasi dan $\mathrm{pH}_{\mathrm{FOx}}$ terendah dijumpai di Kecamatan Malangke. Sebagai akibatnya, potensi kemasaman tertinggi yang digambarkan oleh nilai $\mathrm{pH}_{\mathrm{F}}-\mathrm{pH}_{\mathrm{FOX}}$ tertinggi dijumpai juga di Kecamatan Malangke.

Nilai $S_{\text {Pos }}$ tanah telah digunakan oleh Ahern et al. (1998b) untuk menentukan kebutuhan kapur bagi tanah sulfat masam. Dengan berdasarkan berat jenis tanah sulfat masam yang telah dilaporkan oleh Mustafa (2007) di Kabupaten Luwu yaitu $0,89 \mathrm{~g} / \mathrm{cm}^{3}$ dan nilai $S_{\text {Pos }}$ tanah (Tabel 1) serta berasumsi bahwa kapur pertanian atau kaptan $\left(\mathrm{CaCO}_{3}\right)$ dapat bereaksi sampai kedalaman $5 \mathrm{~cm}$, maka tambak di Kecamatan Malangke Barat, Malangke, Sukamaju, dan Bonebone membutuhkan kaptan (nilai netralisasi $=100$; faktor keamanan $=1,5$ ) masing-masing berturut-turut 27,36; 33,$25 ; 21,01$; dan 39,64 ton/ha. Kebutuhan kapur tertinggi dijumpai di Kecamatan Bonebone yang ditandai juga dengan kandungan unsur toksik seperti Fe (besi) dan Al (aluminium) yang tertinggi juga. Kandungan Fe dan Al yang tinggi di Kecamatan Sukamaju dan Bonebone menyebabkan kandungan $\mathrm{PO}_{4}$ (fosfat) tanah relatif lebih rendah dibandingkan dengan kecamatan lainnya. Hal ini sebagai akibat dari $\mathrm{Fe}$ dan $\mathrm{Al}$ tanah yang dapat menyebabkan $\mathrm{PO}_{4}$ menjadi tidak tersedia.

Potensial redoks tanah menggambarkan kondisi tanah yang tereduksi atau teroksidasi. Dari Tabel 1 terlihat bahwa potensial redoks tanah di Kabupaten Lutra bernilai negatif yang

Tabel 1. Rata-rata nilai setiap peubah kualitas tanah dan tekstur tanah (kedalaman 0-1 m) tambak di Kabupaten Luwu Utara Provinsi Sulawesi Selatan

Table 1. The average value of soil quality variables and soil texture (depth of $0-1 \mathrm{~m}$ ) in the brackishwater ponds of North Luwu Regency South Sulawesi Province

\begin{tabular}{|c|c|c|c|c|}
\hline \multirow{2}{*}{$\begin{array}{l}\text { Peubah } \\
\text { Variables }\end{array}$} & \multicolumn{4}{|c|}{ Kecamat an (Sub-districts) } \\
\hline & $\begin{array}{l}\text { Malangke Barat } \\
\qquad(n=60)\end{array}$ & $\begin{array}{l}\text { Malangke } \\
(n=30)\end{array}$ & $\begin{array}{l}\text { Sukamaju } \\
(n=18)\end{array}$ & $\begin{array}{l}\text { Bonebone } \\
(n=179)\end{array}$ \\
\hline $\mathrm{pH}_{\mathrm{F}}$ & 6.71 & 6.58 & 6.78 & 6.79 \\
\hline $\mathrm{pH}_{\mathrm{FOX}}$ & 1.18 & 0.99 & 1.96 & 1.62 \\
\hline $\mathrm{pH}_{\mathrm{F}}-\mathrm{pH}_{\mathrm{FOX}}$ & 5.53 & 5.59 & 4.82 & 5.17 \\
\hline $\begin{array}{l}\text { Potensial redoks (mV) } \\
\text { Redox potential }\end{array}$ & -289 & -308 & -287 & -283 \\
\hline $\mathrm{S}_{\mathrm{POS}}(\%)$ & 1.343 & 1.6317 & 1.0311 & 1.9455 \\
\hline TPA (mol H+/ton) & 472 & 492 & 689 & 465 \\
\hline $\begin{array}{l}\text { Bahan organik (\%) } \\
\text { Organic matter }\end{array}$ & 8.6902 & 7.5145 & 24.5939 & 9.0694 \\
\hline Pirit (Pyrite) (\%) & 2.0586 & 2.1704 & 3.0268 & 1.9593 \\
\hline $\mathrm{Fe}(\mathrm{mg} / \mathrm{L})$ & 4,290 & 4,714 & 4,487 & 4,951 \\
\hline $\mathrm{Al}(\mathrm{mg} / \mathrm{L})$ & 312 & 271 & 376 & 682 \\
\hline $\mathrm{PO}_{4}(\mathrm{mg} / \mathrm{L})$ & 2.2721 & 3.9799 & 0.6487 & 0.9069 \\
\hline Pasir (Sand) (\%) & 62.8 & 72.2 & 80.3 & 64 \\
\hline Liat (Clay) (\%) & 0.2 & 0.6 & 0.5 & 0.3 \\
\hline Debu (Silt) (\%) & 37 & 27.2 & 19.2 & 35.7 \\
\hline $\begin{array}{l}\text { Tekstur } \\
\text { Texture }\end{array}$ & $\begin{array}{l}\text { Pasir (Sand), Pasir } \\
\text { berlempung } \\
\text { (Loamy sand), } \\
\text { Lempung berpasir } \\
\text { (Sandy loam), } \\
\text { Lempung berdebu } \\
\text { (Silty loam) }\end{array}$ & $\begin{array}{l}\text { Pasir (Sand), } \\
\text { Lempung } \\
\text { berpasir } \\
\text { (Sandy loam), } \\
\text { Pasir } \\
\text { berlempung } \\
\text { (Loamy sand) }\end{array}$ & $\begin{array}{c}\text { Pasir } \\
\text { berlempung } \\
\text { (Loamy sand), } \\
\text { Lempung } \\
\text { berpasir } \\
\text { (Sandy loam) }\end{array}$ & $\begin{array}{l}\text { Pasir berlempung } \\
\text { (Loamy sand), } \\
\text { Lempung } \\
\text { berpasir (Sandy } \\
\text { loam ), Lempung } \\
\text { berdebu (Silty } \\
\text { loam) }\end{array}$ \\
\hline
\end{tabular}


berarti tanah dalam kondisi tereduksi. Hal ini sebagai akibat tanah yang telah lama tergenang pada saat pengambilan contoh tanah, sehingga terbentuk kondisi reduksi pada tanah dasar tambak.

Kandungan bahan organik tanah di Kecamatan Malangke Barat, Malangke, dan Bonebone, jauh lebih rendah dibandingkan dengan kandungan bahan organik tanah di Kecamatan Sukamaju. Tambak di Kecamatan Sukamaju umumnya dibangun pada tanah gambut atau tanah sulfat masam yang berasosiasi dengan tanah gambut. Tanah gambut adalah tanah yang dicirikan dengan kandungan C-organik (karbon-organik) yang tinggi yaitu melebihi $18 \%$.

Kandungan pasir umumnya tinggi (lebih besar 60\%) dan sebaliknya kandungan liat sangat rendah (kurang dari 1\%) di setiap kecamatan di Kabupaten Lutra. Tekstur tanah yang demikian tergolong tekstur yang kurang menguntungkan secara fisik untuk konstruksi pematang tambak. Secara kimia, tekstur tanah demikian juga tidak mampu menyimpan unsur hara dan memiliki daya sangga tanah yang rendah sehingga fluktuasi $\mathrm{pH}$ dapat lebih besar. Tanah tambak dengan kandungan liat 5-10\% tergolong baik untuk budidaya tambak.

\section{Topografi}

Tambak di kawasan pesisir Kabupaten Lutra umumnya dibangun pada areal yang sebelumnya adalah kawasan mangrove. Secara umum kawasan mangrove berada pada topografi yang relatif datar dan elevasi yang dapat dijangkau oleh pasang surut agar mangrove dapat hidup dan berkembang. Dengan demikian, topografi kawasan tambak di Kabupaten Lutra tergolong rendah dan datar. Hal ini juga terlihat pada peta Kelerengan Kabupaten Lutra yang menggambarkan bahwa kawasan pesisir Kabupaten Lutra memiliki kelerengan kurang dari 8\%. Chanratchakool et al. (1995) menyarankan lahan yang baik untuk budidaya tambak adalah relatif datar. Pada lahan yang relatif datar dan elevasi yang tidak tinggi maka tambak dapat dikonstruksi dengan biaya relatif murah dan pengelolaan tambak juga dapat relatif murah.

\section{Hidrologi}

Kisaran pasang surut di kawasan pesisir Kabupaten Lutra sebesar 2,55 m (Gambar 1). Kisaran pasang surut ini relatif sama dengan yang telah dilaporkan oleh peneliti terdahulu di kabupaten lain di pantai timur Sulawesi Selatan. Di Kecamatan Malili (sebelumnya Kabupaten Luwu, sekarang termasuk Kabupaten Lutim) didapatkan kisaran pasang surut sebesar 2,30 m oleh Mustafa et al. (1994). Kisaran pasang surut yang ideal untuk tambak budidaya udang adalah antara 1,5 dan 2,5 m. Dengan kisaran pasang surut yang demikian itu di Kabupaten Lutra menunjukkan bahwa dengan elevasi tambak yang tepat maka

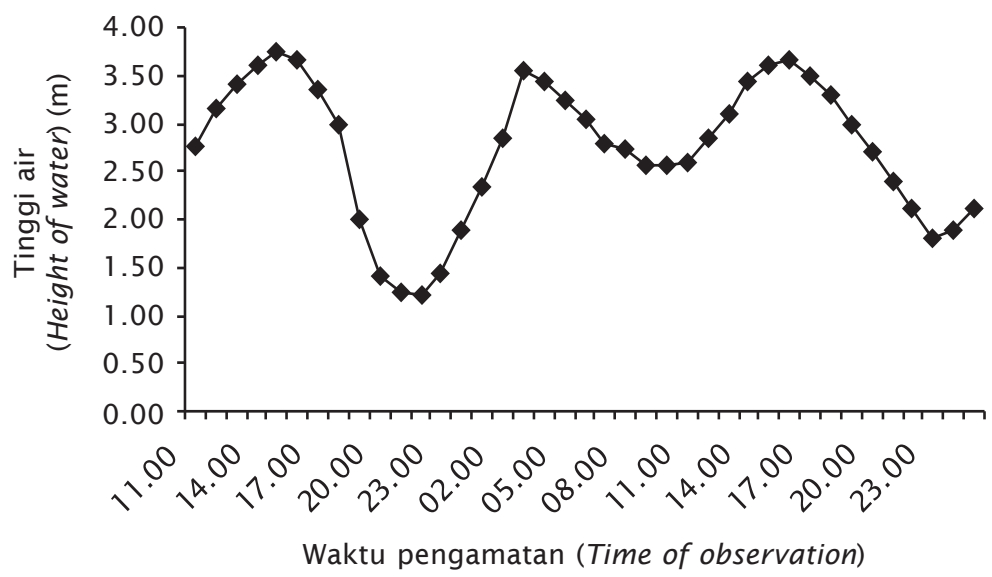

Gambar 1. Pasang surut di kawasan pesisir Kabupaten Luwu Utara Provinsi Sulawesi Selatan

Figure 1. Tidal range in the coastal area of North Luwu Regency, South Sulawesi Province 
tambak dapat dikeringkan dan diisi air secara gravitasi, tetapi pematang terpaksa dibuat lebih lebar dan tinggi agar mampu menahan tekanan air waktu pasang tinggi dan surut rendah. Hal ini terlihat pada saat penelitian dilaksanakan dimana banyak tambak di Desa Munte, Kecamatan Bonebone yang pematang tambaknya dilewati oleh air pada saat pasang tinggi.

Pada musim hujan, salinitas air tambak yang terendah dijumpai di Kecamatan Malangke yaitu dengan rata-rata 8 ppt (Tabel 2). Hal demikian juga terjadi pada musim kemarau di mana salinitas terendah (18 ppt) juga dijumpai di Kecamatan Malangke (Tabel 3). Secara umum, salinitas lebih tinggi pada musim kemarau dibandingkan dengan musim hujan pada lokasi yang sama. Air hujan dapat menurunkan salinitas air. Hal yang sama juga terjadi pada suhu air tambak di mana ada kecenderungan lebih tingginya suhu air pada musim kemarau dibandingkan dengan musim hujan.

Oksigen terlarut relatif sama di setiap kecamatan walaupun pada musim yang berbeda. Pada lokasi yang sama, $\mathrm{pH}$ air tambak cenderung lebih rendah pada musim hujan. Hal ini dapat disebabkan oleh tercucinya asam-asam dari tanah pematang pada saat musim hujan. Hal yang juga berbeda adalah kandungan bahan organik total air yang cenderung lebih tinggi pada musim kemarau. Juga terlihat dengan jelas tingginya kandungan bahan organik total air di Kecamatan Sukamaju dibandingkan dengan kecamatan lain, baik musim hujan maupun kemarau. Hal ini sangat terkait dengan jenis tanah tambak, seperti telah disebutkan sebelumnya bahwa tambak di Kecamatan Sukamaju tergolong tanah gambut atau tanah sulfat masam yang ber-

Tabel 2. Rata-rata nilai setiap peubah kualitas air tambak pada musim hujan di Kabupaten Luwu Utara Provinsi Sulawesi Selatan

Table 2. The average value of water quality variables in the brackishwater ponds in rainy season of North Luwu Regency South Sulawesi Province

\begin{tabular}{|c|c|c|c|c|}
\hline \multirow{2}{*}{$\begin{array}{l}\text { Peubah } \\
\text { Variables }\end{array}$} & \multicolumn{4}{|c|}{ Kecamatan (Sub-districts) } \\
\hline & $\begin{array}{l}\text { Malangke Barat } \\
\quad(n=19)\end{array}$ & $\begin{array}{l}\text { Malangke } \\
(n=10)\end{array}$ & $\begin{array}{l}\text { Sukamaju } \\
\quad(n=6)\end{array}$ & $\begin{array}{l}\text { Bonebone } \\
(n=27)\end{array}$ \\
\hline Salinitas (Salinity) (ppt) & 8 & 16 & 19 & 17 \\
\hline Suhu (Temperature) $\left({ }^{\circ} \mathrm{C}\right)$ & 32.88 & 32.34 & 32.07 & 33.31 \\
\hline $\begin{array}{l}\text { Oksigen te rlarut }(\mathrm{mg} / \mathrm{L}) \\
\text { Dissolved oxygen }\end{array}$ & 7.15 & 6.03 & 5.36 & 5.18 \\
\hline $\mathrm{pH}$ & 8.48 & 8.67 & 8.51 & 8.36 \\
\hline $\begin{array}{l}\text { Bahan organik total }(\mathrm{mg} / \mathrm{L}) \\
\text { Total organic matter }\end{array}$ & 10.35 & 3.51 & 3.87 & 5.03 \\
\hline $\mathrm{NH}_{4}(\mathrm{mg} / \mathrm{L})$ & 0.0831 & 0.0167 & 0.0396 & 0.0140 \\
\hline $\mathrm{NO}_{2}(\mathrm{mg} / \mathrm{L})$ & 0.0022 & 0.0128 & 0.0063 & 0.0036 \\
\hline $\mathrm{NO}_{3}(\mathrm{mg} / \mathrm{L})$ & 0.0102 & 0.0096 & 0.0232 & 0.0124 \\
\hline $\mathrm{PO}_{4}(\mathrm{mg} / \mathrm{L})$ & 0.0266 & 0.0457 & 0.0219 & 0.0114 \\
\hline $\mathrm{SiO}_{2}(\mathrm{mg} / \mathrm{L})$ & 0.1219 & 0.0530 & 0.0555 & 0.0258 \\
\hline $\mathrm{Fe}(\mathrm{mg} / \mathrm{L})$ & 0.0417 & 0.0308 & 0.0456 & 0.0414 \\
\hline $\mathrm{SO}_{4}(\mathrm{mg} / \mathrm{L})$ & 95.40 & 19.35 & 21.00 & 25.60 \\
\hline $\begin{array}{l}\text { Ke sadahan } \mathrm{Ca}(\mathrm{mg} / \mathrm{L}) \\
\text { Ca hardness }\end{array}$ & 23.87 & 28.29 & 35.47 & 33.37 \\
\hline $\begin{array}{l}\text { Kesadahan } \mathrm{Mg}(\mathrm{mg} / \mathrm{L}) \\
\text { Mg hardness }\end{array}$ & 149.40 & 211.62 & 217.83 & 246.36 \\
\hline $\begin{array}{l}\text { Kesadahan total }(\mathrm{mg} / \mathrm{L}) \\
\text { Total hardness }\end{array}$ & 173.27 & 239.91 & 253.30 & 279.73 \\
\hline
\end{tabular}


asosiasi dengan tanah gambut yang dicirikan dengan kandungan bahan organik tanah yang tinggi.

Dari berbagai bentuk nitrogen dalam air yang dianalisis, terlihat kandungan $\mathrm{NO}_{3}$ (nitrat) air lebih tinggi pada musim hujan daripada musim kemarau. Telah kita ketahui bahwa nitrogen oksida berupa $\mathrm{NO}_{3}$ terdapat di atmosfer dan selanjutnya turun ke bumi bersama air hujan yang berdampak pada tingginya kandungan $\mathrm{NO}_{3}$ air pada musim hujan. Air hujan mengandung $\mathrm{NO}_{3}$ sebesar 0,2 mg/L (Effendi, 2003).

Kandungan $\mathrm{SiO}_{2}$ (silika) air tambak memiliki kecenderungan yang sama pada musim yang berbeda di Kabupaten Lutra. Baik pada musim hujan maupun musim kemarau, kandungan $\mathrm{SiO}_{2}$ tertinggi didapatkan di Kecamatan Sukamaju dan terendah di Kecamatan Bonebone. Silikon (Si) di alam tidak ditemukan dalam bentuk elemen bebas, tetapi dalam bentuk $\mathrm{SiO}_{2}$ dan terlihat bahwa kandungan $\mathrm{SiO}_{2}$ air lebih tinggi pada musim kemarau dibandingkan dengan musim hujan. Secara umum, kandungan $\mathrm{SiO}_{2}$ air lebih tinggi pada air laut daripada air payau dan tawar, sehingga salinitas yang lebih tinggi menjadi faktor penyebab tingginya kandungan $\mathrm{SiO}_{2}$ pada musim kemarau. Mustafa (2007) juga menyatakan bahwa kandungan $\mathrm{SiO}_{2}$ lebih tinggi pada saat pasang daripada saat surut sebagai akibat salinitas yang lebih tinggi pada saat pasang.

Besi yang melimpah pada tanah sulfat masam sebagai hasil oksidasi pirit dan pada musim hujan menjadi larut ke dalam tambak sehingga kandungan Fe air pada musim hujan

Tabel 3. Rata-rata nilai setiap peubah kualitas air tambak pada musim kemarau di Kabupaten Luwu Utara Provinsi Sulawesi Selatan

Table 3. The average value of water quality variables in the brackishwater ponds in the dry season of North Luwu Regency South Sulawesi Province

\begin{tabular}{|c|c|c|c|c|}
\hline \multirow{2}{*}{$\begin{array}{l}\text { Peubah } \\
\text { Variables }\end{array}$} & \multicolumn{4}{|c|}{ Kecamatan (Sub-dist ricts) } \\
\hline & $\begin{array}{l}\text { Malangke Barat } \\
\qquad(n=17)\end{array}$ & $\begin{array}{l}\text { Malangke } \\
\quad(n=8)\end{array}$ & $\begin{array}{l}\text { Sukamaju } \\
(n=4)\end{array}$ & $\begin{array}{c}\text { Bonebone } \\
(n=23)\end{array}$ \\
\hline Salinitas (Salinity) (ppt) & 18 & 28 & 30 & 21 \\
\hline Suhu (Temperature) $\left({ }^{\circ} \mathrm{C}\right)$ & 32.34 & 35.14 & 33.41 & 31.67 \\
\hline $\begin{array}{l}\text { Oksigen te rlarut }(\mathrm{mg} / \mathrm{L}) \\
\text { Dissolved oxygen }\end{array}$ & 6.32 & 6.32 & 4.91 & 5.14 \\
\hline $\mathrm{pH}$ & 8.53 & 8.74 & 8.54 & 8.44 \\
\hline $\begin{array}{l}\text { Bahan organik total }(\mathrm{mg} / \mathrm{L}) \\
\text { Total organic matter }\end{array}$ & 10.49 & 9.33 & 9.05 & 8.86 \\
\hline $\mathrm{NH}_{4}(\mathrm{mg} / \mathrm{L})$ & 0.0273 & 0.0329 & 0.0366 & 0.0250 \\
\hline $\mathrm{NO}_{2}(\mathrm{mg} / \mathrm{L})$ & 0.0052 & 0.0038 & 0.0041 & 0.0036 \\
\hline $\mathrm{NO}_{3}(\mathrm{mg} / \mathrm{L})$ & 0.0088 & 0.0041 & 0.0024 & 0.0052 \\
\hline $\mathrm{PO}_{4}(\mathrm{mg} / \mathrm{L})$ & 0.0320 & 0.0294 & 0.0139 & 0.0350 \\
\hline $\mathrm{SiO}_{2}(\mathrm{mg} / \mathrm{L})$ & 0.3961 & 0.0884 & 0.1341 & 0.0311 \\
\hline $\mathrm{Fe}(\mathrm{mg} / \mathrm{L})$ & 0.0018 & 0.0026 & 0.0025 & 0.0019 \\
\hline $\mathrm{SO}_{4}(\mathrm{mg} / \mathrm{L})$ & 360.13 & 404.43 & 416.66 & 417.03 \\
\hline $\begin{array}{l}\text { Ke sadahan Ca }(\mathrm{mg} / \mathrm{L}) \\
\text { Ca hardness }\end{array}$ & 81.40 & 87.87 & 156.08 & 159.46 \\
\hline $\begin{array}{l}\text { Ke sadahan } \mathrm{Mg}(\mathrm{mg} / \mathrm{L}) \\
\text { Mg hardness }\end{array}$ & 443.52 & 380.00 & 451.58 & 252.35 \\
\hline $\begin{array}{l}\text { Kesadahan total }(\mathrm{mg} / \mathrm{L}) \\
\text { Total hardness }\end{array}$ & 524.92 & 467.87 & 607.66 & 411.81 \\
\hline $\begin{array}{l}\text { Padatan tersuspensi total (mg/L) } \\
\text { Total suspended solid }\end{array}$ & 69 & 70 & 116 & 61 \\
\hline
\end{tabular}


dapat 20 kali lipat dibandingkan musim kemarau. Sebaliknya $\mathrm{SO}_{4}$ (sulfat) juga sekitar 20 kali lipat lebih tinggi kandungannya dalam air pada musim kemarau dibandingkan dengan musim hujan. Mustafa (2007) menyatakan bahwa ketika salinitas meningkat maka akan diikuti dengan peningkatan kandungan $\mathrm{SO}_{4}$ air tambak di Kecamatan Walenrang, Kabupaten Luwu. Kecenderungan yang sama juga terlihat pada kesadahan Ca (kalsium), kesadahan $\mathrm{Mg}$ (magnesium), dan kesadahan total air tambak yang lebih tinggi pada musim kemarau dibandingkan dengan musim hujan.

Padatan tersuspensi total menggambarkan bahan-bahan tersuspensi (diameter $>1 \mu \mathrm{m}$ ) yang terdiri atas lumpur dan pasir halus serta jasad renik yang terutama disebabkan oleh erosi yang terbawa ke dalam air. Kandungan padatan tersuspensi air tertinggi didapatkan di Kecamatan Sukamaju.

\section{Vegetasi}

Spesies vegetasi yang dijumpai pada kawasan pesisir Kabupaten Lutra berjumlah 22 spesies yang tergolong dalam 18 genus dan 16 famili (Tabel 4). Tingkat kekayaan spesies vegetasi mangrove ini tergolong cukup tinggi. Di Indonesia, menurut Wirakusuma \& Sutrisno (1978) dalam Mustafa et al. (1988) pada mulanya diperkirakan terdapat sekitar 26 spesies vegetasi penyusun hutan mangrove, namun perhitungan terakhir menunjukkan ada 35 spesies (Sukardjo, 1985). Dari 18 genus yang ada di Kabupaten Lutra ternyata terdapat 5 genus yang termasuk halopitik atau vegetasi yang menyukai tanah yang bergaram yaitu Avicennia sp., Bruguiera sp., Lumnitzera sp., Rhizophora sp., dan Xylocarpus sp. Kelompok vegetasi tersebut merupakan vegetasi yang menentukan ciri dari hutan mangrove

Tabel 4. Spesies vegetasi mangrove yang dijumpai di kawasan pesisir Kabupaten Luwu Utara Provinsi Sulawesi Selatan

Table 4. Species of mangrove vegetation found in coastal area of North Luwu Regency South Sulawesi Province

\begin{tabular}{|c|c|c|}
\hline $\begin{array}{l}\text { Famili } \\
\text { Family }\end{array}$ & $\begin{array}{l}\text { Genus } \\
\text { Genera }\end{array}$ & $\begin{array}{l}\text { Spesies } \\
\text { Species }\end{array}$ \\
\hline Ac anthac eae & Ac anthus & Acanthus ilicifolius L. \\
\hline Apocynaceae & Cerbera & Cerbera manghas L. \\
\hline Avicenniaceae & Avicennia & Avicennia marina (Forsk.) Vier. \\
\hline Bignoniaceae & Dolichandrone & Dolichandrone spathacea Seem. \\
\hline Combretaceae & Lumnitzera & Lumnitzera littorea (Jack.) Voigt. \\
\hline Leguminosae & Intsia & Intsia bijuga (Colebr.) O. Ktze. \\
\hline Malvaceae & Hibiscus & Hibiscus tiliaceus \\
\hline Meliace ae & Xylocarpus & $\begin{array}{l}\text { Xylocarpus granatum Koenig } \\
\text { Xylocarpus moluccensis (L.) Roem }\end{array}$ \\
\hline Myrsinaceae & Aegice ras & Aegiceras corniculatum (L.) Blanco \\
\hline Palmae & Nypa & Nypa fruticans Thunb. \\
\hline Pandanaceae & Pandanus & Pandanus candelabrum \\
\hline Polypodiaceae & Acrostichum & Acrostichum aureum \\
\hline \multirow[t]{3}{*}{ Rhizophoraceae } & Rhizophora & $\begin{array}{l}\text { Rhizophora apiculata Blume } \\
\text { Rhozophora mucronata Lamk }\end{array}$ \\
\hline & Bruguiera & $\begin{array}{l}\text { Bruguiera gymnorrhiza (L.) Lamk } \\
\text { Bruguiera parviflora (Roxb.)W. }\end{array}$ \\
\hline & Ceriops & Ceriops tagal (Perr.) C. B. Rob \\
\hline Rubiaceae & Scyphiphora & Scyphiphora hydrophyllaceae Gaertn \\
\hline Sonneratiaceae & Sonneratia & $\begin{array}{l}\text { Sonneratia acida } \\
\text { Sonneratia alba Sm. }\end{array}$ \\
\hline Sterculiaceae & He ritiera & Heritiera littoralis Drynand \\
\hline
\end{tabular}


berdasarkan sebaran dan merupakan vegetasi eksklusif yang sangat terikat pada habitat mangrove. Hutan mangrove juga dicirikan dengan adanya vegetasi non-eksklusif yang tidak terikat pada habitat yang ternyata juga dijumpai di kawasan pesisir Kabupaten Lutra seperti paku laut (Acrostichum aureum) dan waru laut (Hibiscus tiliaceus).

Telah disebutkan sebelumnya bahwa tanah di kawasan pesisir Kabupaten Lutra tergolong tanah sulfat masam atau tanah gambut atau tanah sulfat masam yang berasosiasi dengan tanah gambut dan hal ini diperjelas dengan vegetasi yang ditemukan di kawasan tersebut. Paku laut dan bakau (Rhizophora sp.) adalah vegetasi yang dapat dijadikan sebagai indikator tanah sulfat masam (Mustafa, 2007). Jamandre \& Rabanal (1975) menyatakan bahwa nipah (Nypa fruticans) dikenal sebagai vegetasi yang tinggi kandungan taninnya yang akan mempengaruhi tambak karena akan menyebabkan tanah masam. Telah dilaporkan sebelumnya oleh Mustafa et al. (1988) bahwa kawasan mangrove di Kecamatan Bonebone didominasi berturut-turut oleh Sonneratia alba, Nypa fruticans, Rhizophora apiculata, Rhizophora mucronata, dan Bruguiera gymnorrhiza dengan nilai penting berturutturut 78,39\%; 76,55\%; 68,43\%; 20,18\%; dan $16,24 \%$.

\section{Iklim}

Salah satu faktor yang sangat berpengaruh terhadap budidaya tambak termasuk kualitas air tambak adalah iklim, terutama curah hujan. Curah hujan bulanan di Kabupaten Lutra dapat dilihat pada Gambar 2 dan menunjukkan bahwa setiap bulan terjadi hujan dengan curah hujan melebihi $100 \mathrm{~mm} /$ bulan. Curah hujan bulanan yang rendah dijumpai pada September sampai Februari dan curah hujan yang lebih tinggi dijumpai pada bulan lainnya yaitu dari Maret sampai Agustus terutama di Kecamatan Bonebone. Pengambilan contoh air tambak pada bulan April (mewakili musim hujan) dan bulan Oktober (mewakili musim kemarau) berdampak pada adanya perbedaan kualitas air tambak di Kabupaten Lutra (Tabel 2 dan 3).

Curah hujan di Kecamatan Bonebone, termasuk Sukamaju adalah $2.863 \mathrm{~mm} /$ tahun dan di Kecamatan Malangke, termasuk Malangke Barat adalah $3.136 \mathrm{~mm} / \mathrm{tahun}$. Curah hujan antara 2.000-3.000 mm/tahun dengan bulan kering 2-3 bulan cukup baik digunakan untuk tambak. Dengan demikian curah hujan di Kecamatan Bonebone dan Sukamaju tergolong baik untuk budidaya tambak dan di kecamatan lainnya tergolong kurang mendukung untuk usaha budidaya tambak. Persiapan tambak adalah salah satu kegiatan yang harus dilakukan sebelum dilakukan

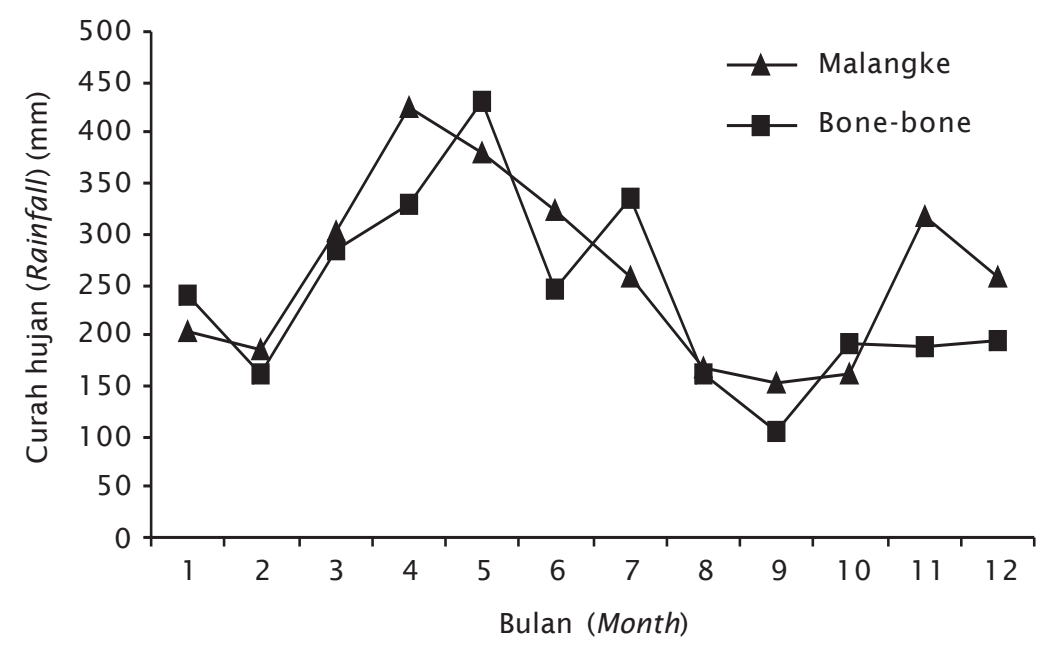

Gambar 2. Curah hujan bulanan di kawasan pesisir Kabupaten Luwu Utara Provinsi Sulawesi Selatan

Figure 2. Monthly rainfall in the coastal area of North Luwu Regency South Sulawesi Province 
penebaran. Pada saat persiapan tambak dilakukan pengeringan tambak dengan tujuan untuk memperbaiki sifat fisik tanah, meningkatkan mineralisasi bahan organik dan menghilangkan bahan-bahan beracun berupa hidrogen sulfida, amonia, dan metan. Karena itu diperlukan adanya bulan-bulan kering tertentu pada setiap tahun. Bulan Agustus dan September serta Januari dan Februari adalah saat yang tepat dalam melaksanakan persiapan tambak di Kabupaten Lutra.

\section{Kesesuaian dan Pengelolaan Lahan}

Hasil analisis menunjukkan bahwa dari luas potensial lahan tambak di Kabupaten Lutra, ternyata $1.821,9$ ha tergolong sangat sesuai (kelas S1); 368,2 ha tergolong cukup sesuai (kelas S2); dan 3.268,1 ha tergolong sesuai marjinal (kelas S3) (Gambar 3). Berdasarkan Pasal 27 Keppres Nomor 32 tahun 1990 tentang Pengelolaan Kawasan Lindung dan kisaran pasang surut di Kabupaten Lutra maka lebar jalur hijau di tepi pantai sekitar $332 \mathrm{~m}$ dan berdasarkan Pasal 16 Keppres Nomor 32 tahun 1990 tentang Pengelolaan Kawasan Lindung maka lebar jalur hijau di tepi kiri dan kanan sungai adalah $100 \mathrm{~m}$.
Sebagai faktor pembatas utama kesesuaian lahan tambak di Kabupaten Lutra adalah potensi kemasaman tanah yang tinggi terutama di Kecamatan Malangke. Pengelolaan lahan terutama tanah yang dapat dilakukan untuk menurunkan potensi kemasaman tanah adalah melalui remediasi baik berupa pengeringan dan pembilasan tanah maupun melalui pengapuran. Selain perbaikan tanah, rekayasa tambak tepat dapat pula mengoptimumkan produksi di tambak tanah sulfat masam. Untuk mengurangi masuknya asamasam organik dari pematang ke dalam tambak pada saat hujan (terutama setelah panas yang lama), maka pada tambak tanah sulfat masam sebaiknya pematang diberi berm dan ditanami rumput (Mustafa et al., 1992; Mustafa, 2008). Penanaman rumput pada pematang ini juga dapat mengurangi erosi pematang. Selain itu, untuk mengurangi masuknya asam-asam organik dari dalam tanah pematang tambak yang dibangun di tanah sulfat masam, disarankan melakukan pengapuran berlapis atau integrasi kapur ke dalam tanah pematang pada saat pembuatan pematang baru atau rekonstruksi pematang. Sebaiknya, gundukan tanah yang ada dalam tambak dikurangi dan
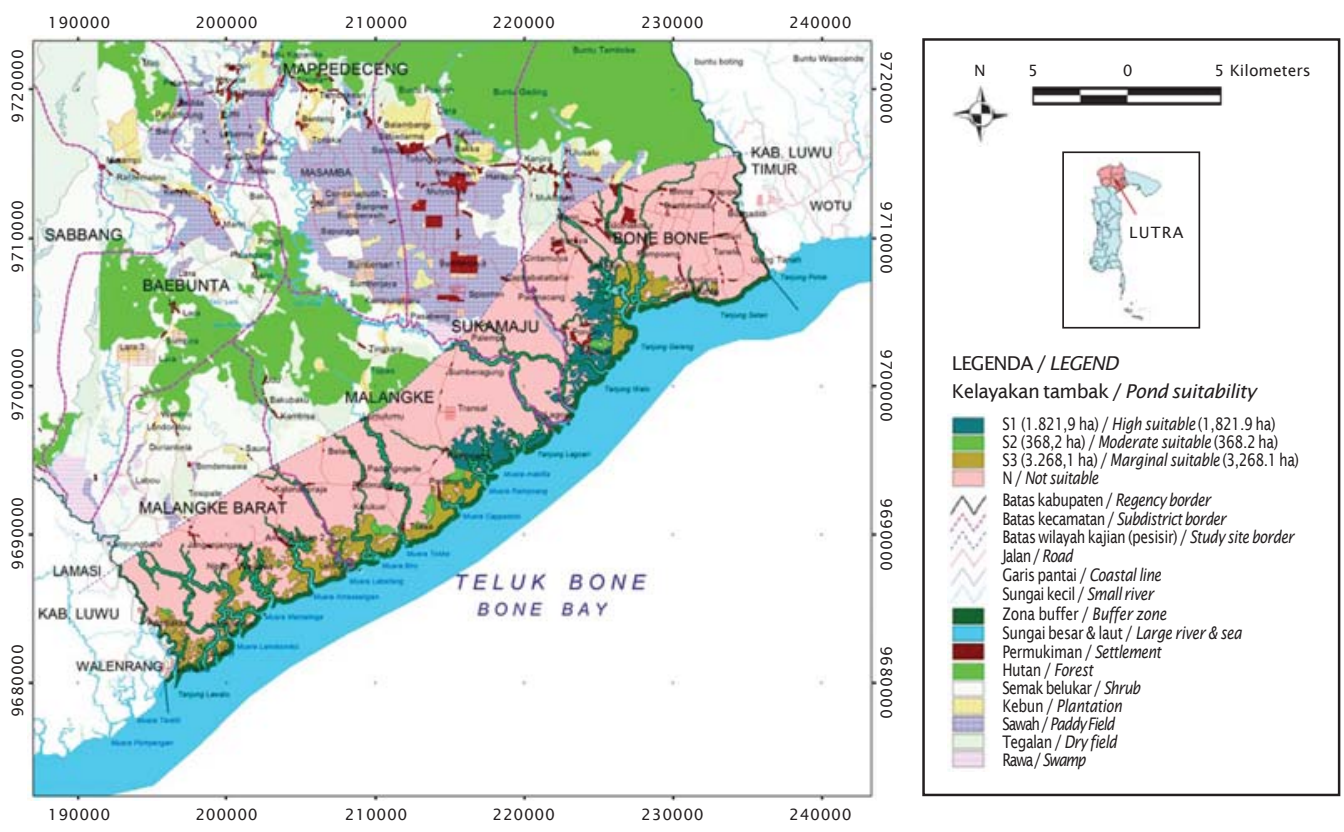

Gambar 3. Kesesuaian lahan tambak di Kabupaten Luwu Utara Provinsi Sulawesi Selatan

Figure 3. Land suitability for brackishwater ponds in North Luwu Regency South Sulawesi Province 
kalau perlu ditiadakan, sebab kondisi ini menyebabkan semakin luas permukaan tanah sulfat masam yang teroksidasi, sehingga unsur atau senyawa beracun juga semakin bertambah.

Tambak yang dibangun pada tanah sulfat masam berukuran lebih dari 0,5 ha dengan kedalaman air 1,0 $\mathrm{m}$ atau lebih pada setiap saat cukup ideal untuk budidaya udang windu. Ukuran tambak yang lebih besar menyebabkan rasio panjang pematang:Iuas tambak menjadi lebih kecil, sehingga asam-asam organik yang terlarut dari pematang pada saat hujan tidak terlalu drastis menyebabkan penurunan $\mathrm{pH}$ dan peningkatan unsur atau senyawa beracun. Mempertahankan tinggi air yang sama dalam petakan tambak yang berdekatan dan mengusahakan air dalam petakan tambak lebih tinggi dari yang ada dalam saluran untuk mengurangi masuknya unsur atau senyawa beracun ke dalam petakan tambak secara peresapan melalui pematang.

Bahan organik tanah yangsangat tinggi juga dapat menjadi faktor pembatas dalam kesesuaian lahan tambak di Kecamatan Sukamaju. Penggunaan pupuk yang mengandung nitrogen diharapkan dapat menurunkan rasio C: $\mathrm{N}$ tanah yang juga dapat mempercepat proses penguraian bahan organik. Penguraian bahan organik dapat pula dipercepat melalui remediasi.

Tekstur tanah yang tergolong kasar termasuk tekstur tanah berpasir juga dapat menjadi faktor pembatas kesesuaian lahan tambak di Kabupaten Lutra, terutama untuk penerapan teknologi tradisional. Tambak dengan tekstur tanah kasar sangat sulit untuk penumbuhan klekap yang merupakan makan penting bagi organsime yang dibudidayakan dengan teknologi tradisional. Tambak dengan tanah bertekstur kasar seperti pasir berlempung dan pasir memiliki tingkat porositas yang tinggi, sebagai akibatnya tambak tidak bisa menahan air. Tanah tambak sering dijumpai bertekstur halus dengan kandungan liat minimal 20-30\% untuk menahan peresapan ke samping (Boyd, 1995). Tekstur tanah yang baik untuk tambak adalah: liat, lempung berliat, lempung liat berdebu, lempung berdebu, lempung, dan lempung liat berpasir (Ilyas et al., 1987).

Pada musim hujan, salinitas air yang sangat rendah, sekitar 8 ppt dapat menjadi faktor pembatas kesesuaian lahan tambak di Kecamatan Sukamaju. Udang windu, bandeng dan rumput laut merupakan organisme eurihalin, namun karena dibudidayakan untuk tujuan komersial, kisaran salinitas yang optimum perlu dipertahankan. Salinitas optimum untuk udang windu (Poernomo, 1988) dan ikan bandeng (Ismail et al., 1993) adalah 15 sampai dengan 25 ppt. Rumput laut tumbuh optimum pada salinitas 25 ppt (Lin, 1974; Tseng \& Borowitzka, 2003) dan antara 18 dan 30 ppt (Chen, 1976) serta 15 sampai 25 ppt (Anonymous, 1991). Khusus untuk tambak di pantai timur Sulawesi Selatan, termasuk Kabupaten Lutra dijumpai rumput laut tumbuh optimum pada salinitas 25,6 ppt (Mustafa et al., 2007a).

Pada lokasi yang tergolong sangat sesuai disarankan untuk melakukan budidaya udang secara tradisional, pada lokasi yang tergolong cukup sesuai disarankan melakukan budidaya bandeng dan pada lokasi yang kurang sesuai melakukan polikultur rumput laut dengan bandeng pada musim kemarau. Pada musim hujan disarankan untuk tidak melakukan budidaya rumput laut pada daerah yang bersalinitas kurang dari $10 \mathrm{ppt}$.

\section{KESIMPULAN DAN SARAN}

Hasil karakterisasi lahan tambak di Kabupaten Lutra Provinsi Sulawesi Selatan menunjukkan bahwa tanah sulfat masam adalah jenis tanah dominan yang memiliki potensi kemasaman dan unsur-unsur toksik yang tinggi dan sebaliknya unsur hara makro yang rendah dengan tekstur tanah dominan yang tergolong pasir berlempung dan lempung berpasir. Topografi lahan umumnya relatif datar dan elevasi yang tergolong rendah yang didominasi oleh vegetasi Sonneratia sp., Rhiziphora sp., dan Nypa fruticans. Curah hujan yang rendah pada bulan September sampai Februari berdampak pada kondisi kualitas air yang lebih baik terutama pada salinitas, $\mathrm{pH}, \mathrm{Ca}$, dan $\mathrm{Mg}$ yang lebih tinggi daripada musim hujan. Hasil analisis menunjukkan bahwa lahan tambak di Kabupaten Lutra yang tergolong sangat sesuai (kelas S1) seluas 1.821,9 ha, tergolong cukup sesuai (kelas S2) seluas 368,2 ha dan tergolong sesuai marjinal (kelas S3) seluas 3.268, 1 ha. Untuk perbaikan tanah bermasalah tersebut dapat dilakukan melalui remediasi maupun dengan pemupukan. 


\section{UCAPAN TERIMA KASIH}

Diucapkan terima kasih kepada Proyek Anggaran Pendapatan dan Belanja Negara 2007 "Riset Pemetaan dan Daya Dukung Lahan Budidaya Perikanan Pesisir" di Balai Riset Perikanan Budidaya Air Payau, Maros atas biaya pelaksanaan survai. Juga diucapkan terima kasih kepada Proyek ACIAR FIS/2002/076 "Land Capability Assessment and Classification for Sustainable Pond-based, Aquaculture Systems" di Balai Riset Perikanan Budidaya Air Payau, Maros atas penggunaan berbagai peralatan selama survai.

\section{DAFTAR PUSTAKA}

Ahern, C.R. \& Blunden, B. 1998. Designing a soil sampling and analysis program. In: Ahern, C.R., Blunden, B., and Stone, Y. (Eds.), Acid Sulfate Soils Laboratory Methods Guidelines. Acid Sulfate Soil Management Advisory Committee, Wollongbar, NSW, p. 2.1-2.6.

Ahern, C.R., McElnea, A., \& Baker, D.E. 1998a. Peroxide oxidation combined acidity and sulfate. In: Ahern, C.R., B. Blunden and Y. Stone (Eds.), Acid Sulfate Soils Laboratory Methods Guidelines. Acid Sulfate Soil Management Advisory Committee, Wollongbar, NSW, p. 4.1-4.17.

Ahern, C.R., McElnea, A., \& Baker, D.E. 1998b. Total oxidisable sulfur. In: Ahern, C.R., Blunden, B. and Stone, Y. (Eds.), Acid Sulfate Soils Laboratory Methods Guidelines. Acid Sulfate Soil Management Advisory Committee, Wollongbar, NSW, p. 5.1-5.7.

Ahern, C.R. \& Rayment, G.E. 1998. Codes for acid sulfate soils analytical methods. In: Ahern, C.R., Blunden, B. and Stone, Y. (Eds.), Acid Sulfate Soils Laboratory Methods Guidelines. Acid Sulfate Soil Management Advisory Committee, Wollongbar, NSW, p. 3.1-3.5.

Anonim. 2005. Laporan Statistik Perikanan Sulawesi Selatan. Dinas Perikanan dan Kelautan Propinsi Sulawesi Selatan, Makassar, $261 \mathrm{hlm}$.

Anonymous. 1991. Mariculture of seaweeds. In: Shokita, S., Kakazu, K., Tomori, A., and Toma, T. (Eds.), Aquaculture in Tropical Areas. Midori Shobo Co., Ltd., Tokyo, p. 31 95.

APHA (American Public Health Association). 2005. Standard Methods for Examination of Water and Wastewater. APHA-AWWA-WEF, Washington, D.C., 1,185 pp.

Blasco, F. 1984. Taxonomic considerations of the mangrove species. In: Snedaker, S.C. and Snedaker, J.G. (Eds.), The Mangrove Ecosystems: Research Methods. UNESCO, Bungay, p. 81-113.

Bouyoucos, C.J. 1962. Hydrometer method improved for making particle size analysis of soils. Agronomy Journal, 54: 464-465.

Boyd, C.E. 1995. Bottom Soils, Sediment, and Pond Aquaculture. Chapman and Hall, New York, $348 \mathrm{pp}$.

Chanratchakool, P., Turnbull, J.F., Funge-Smith, S., \& Limsuwan, C. 1995. Health Management in Shrimp Ponds. Second edition. Aquatic Animal Health Research Institute, Department of Fisheries, Kasetsart University Campus, Bangkok, 111 pp.

Chapman, V.J. 1984. Botanical surveys in mangrove communities. In: Snedaker, S.C. and Snedaker, J.G. (Eds.), The Mangrove Ecosystems: Research Methods. UNESCO, Bungay, p. 53-80.

Chen, T.P. 1976. Culture of Gracilaria. In: Aquaculture Practices in Taiwan. Page Bros., London, p. 145-149.

Cintrõn, G. \& Novelli, Y.S. 1984. Methods for studying mangrove structure. In: Snedaker, S.C. and Snedaker, J.G. (Eds.), The Mangrove Ecosystems: Research Methods. UNESCO, Bungay, p. 91-113.

van Dieven, C.A., van Keulen, H., Wolf, J., \& Berkhout, J.A.A. 1991. Land evaluation: from intuition to quantification. In: Stewart, B.A. (Ed.), Advances in Soil Science. Springer, New York, p. 139-204.

DKP (Departemen Kelautan dan Perikanan). 2005. Revitalisasi Perikanan Budidaya. Departemen Kelautan dan Perikanan, Jakarta, $275 \mathrm{hlm}$.

Effendi, H. 2003. Telaah Kualitas Air bagi Pengelolaan Sumber Daya dan Lingkungan Perairan. Penerbit Kanisius, Yogyakarta, $258 \mathrm{hlm}$.

FAO (Food and Agriculture Organization). 1985. Guidelines: land evaluation for irrigated agriculture. In: FAO Soil Bulletin 55 . Soil Resources Management and Conservation Service and Water Development Division, FAO, Rome, 231 pp.

Ilyas, S., Cholik, F., Poernomo, A., Ismail, W., Arifudin, R., Daulay, T., Ismail, A., 
Koesoemadinata, S., Rabegnatar, I N.S., Soepriyadi, H., Suharto, H.H., Azwar, Z.I., \& Ekowardoyo, S. 1987. Petunjuk Teknis bagi Pengoperasian Unit Usaha Pembesaran Udang Windu. Pusat Penelitian dan Pengembangan Perikanan, Jakarta, $100 \mathrm{hlm}$.

Ismail, A., Poernomo, A., Sunyoto, P., Wedjatmiko, Dharmadi, \& Budiman, R.A.I. 1993. Pedoman Teknis Usaha Pembesaran Ikan Bandeng di Indonesia. Pusat Penelitian dan Pengembangan Perikanan, Jakarta, 93 hlm.

Jamandre, T.J. \& Rabanal, H.R. 1975. Engineering aspect of brackishwater aquaculture in the South China Sea Region. South China Sea Fish. Dev. and Coord. Prog., Manila, 96 pp.

Lin, M.N. 1974. Culture of Gracilaria. Fish Research Institute, Keelung, Taipei, p. 1-8.

Melville, M.D. 1993. Soil Laboratory Manual. School of Geography, The University of New South Wales, Sydney, 74 pp.

Menon, R.G. 1973. Soil and Water Analysis: A Laboratory Manual for the Analysis of Soil and Water. Proyek Survey O.K.T. Sumatera Selatan, Palembang, 190 pp.

Mustafa, A. 2007. Improving Acid Sulfate Soils for Brackish Water Ponds in South Sulawesi, Indonesia. Ph.D. Thesis. The University of New South Wales, Sydney, 418 pp.

Mustafa, A. 2008. Desain, tata letak dan konstruksi tambak. Media Akuakultur, 3(2): 166-174.

Mustafa, A., Hanafi, A., \& Ahmad, T. 1992. Pengelolaan kawasan hutan mangrove untuk budidaya tambak. Dalam: Sunarno, S., Mansur, H., Rachmansyah, Mustafa A., dan A. Hanafi (Eds.), Prosiding Lokakarya Ilmiah Potensi Sumberdaya Perikanan Maluku. Balai Penelitian Perikanan Budidaya Pantai, Maros, hlm. 124-133.

Mustafa, A., Hanafi, A., Pantjara, B., \& Suwardi. 1994. Karakteristik lahan mangrove di Delta Tampinna, Kabupaten Luwu, Sulawesi Selatan. Dalam: Mansur, H., Rachmansyah, Atmomarsono, M. dan Mustafa, A. (Eds.), Risalah Seminar Hasil Penelitian Perikanan Budidaya Pantai. Balai Penelitian Perikanan Budidaya Pantai, Maros, hlm. 95-105.

Mustafa, A., Sapo, I., Hasnawi, \& Sammut, J. 2007a. Hubungan antara faktor kondisi lingkungan dan produktivitas tambak untuk penajaman kriteria kelayakan lahan: 1. Kualitas air. Jurnal Riset Akuakultur, 2(3): 289-302.
Mustafa, A. \& Sammut, J. 2007. Effect of different remediation techniques and dosages of phosphorus fertilizer on soil quality and klekap production in acid sulfate soil-affected aquaculture ponds. Indonesian Aquaculture Journal, 2(2): 141-157.

Mustafa, A. \& Rachmansyah. 2008. Kebijakan dalam pemanfaatan tanah sulfat masam untuk budidaya tambak. Dalam: A. Sudradjat, I W. Rusastra, \& S. Budiharsono (Eds.), Analisis Kebijakan Pembangunan Perikanan Budidaya. Pusat Riset Perikanan Budidaya, Jakarta, hlm. 1-11.

Mustafa, A., Rachmansyah, \& Hanafi, A. 2007b. Kelayakan Lahan untuk Budi Daya Perikanan Pesisir. Dalam: Kumpulan Makalah Bidang Riset Perikanan Budidaya. Disampaikan pada Simposium Kelautan dan Perikanan pada tanggal 7 Agustus 2007 di Gedung Bidakara, Jakarta. Pusat Riset Perikanan Budidaya, Jakarta, $28 \mathrm{hlm}$.

Mustafa, A., Tarunamulia, \& Sammut, J. 2007c. Klasifikasi Kesesuaian Lahan untuk Budidaya Tambak di Indonesia. Balai Riset Perikanan Budidaya Air Payau, Maros, 31 hlm.

Mustafa, A., Ahmad, T., \& Cholik, F. 1988. Vegetasi hutan mangrove di Kecamatan Bone-bone, Kabupaten Luwu, Sulawesi Selatan. Jurnal Penelitian Budidaya Pantai, 4(1): 104-118.

Paena, M., Mustafa, A., Hasnawi, \& Rachmansyah. 2008. Validasi luas periodik dan penentuan luas potensi tambak di Kabupaten Luwu Utara Provinsi Sulawesi Selatan dengan menggunakan teknologi penginderaan jauh dan sistem informasi geografis. Jurnal Riset Akuakultur, 3(1): 137-146.

Parsons, T.R., Maita, Y., \& Lalli, C.M. 1989. A Manual of Chemical and Biological Methods for Seawater Analysis. Pergamon Press, Oxford, $173 \mathrm{pp}$.

Pérez, O.M., Ross, L.G., Telfer, T.C., and del Campo Barquin, L.M. 2003. Water quality requirements for marine fish cage site selection in Tenerife (Canary Islands): predictive modelling and analysis using GIS. Aquaculture, 224: 51-68.

Poernomo, A. 1988. Pembuatan Tambak Udang di Indonesia. Seri Pengembangan No. 7. Balai Penelitian Perikanan Budidaya Pantai, Maros, $30 \mathrm{hlm}$.

Purwadhi, F.S.H. 1999. Sistem Informasi Geografis. Dalam: Suharmanto, Tjinda, F., 
Yulmontoro, S., Arisdyo, I.L., Ginting, R., dan Effendi, A. (Eds.), Pengantar Teknologi, Aplikasi Penginderaan Jauh Satelit dan Sistem Informasi Geografi. Lembaga Penerbangan dan Antariksa Nasional dan Badan Pengkajian dan Penerapan Teknologi, Jakarta, hlm. 367-494.

Rayes, M.L. 2007. Metode Inventarisasi Sumber Daya Lahan. Penerbit Andi, Yogyakarta, 298 hlm.

Rossiter, D.G. 1996. A. theoretical framework for land evaluation. Geoderma, 72: 165202.
Sukardjo, S. 1985. Hutan berair melimpah di Indonesia. Oseana, 10(2): 62-77.

Sulaeman, Suparto, \& Eviati. 2005. Petunjuk Teknis Analisis Kimia Tanah, Tanaman, Air, dan Pupuk. Dalam: Prasetyo, B.H., Santoso, D., dan Widowati, L.R. (Eds.). Balai Penelitian Tanah, Bogor, $136 \mathrm{hlm}$.

Tseng, C.K. \& Borowitzka, M. 2003. Algae culture. In: Lucas, J.S. and Southgate, P.C. (Eds.), Aquaculture: Farming Aquatic Animals and Plants. Blackwell Publishing Ltd., Oxford, p. 253-275. 